\title{
Application of Extracellular Gadolinium-based MRI Contrast Agents and the Risk of Nephrogenic Systemic Fibrosis
}

\author{
Anwendung von extrazellulären gadoliniumhaltigen \\ MR-Kontrastmitteln und Risiko der Nephrogenen \\ Systemischen Fibrose
}

Authors

Affiliations
J. T. Heverhagen ${ }^{1}$, G. A. Krombach ${ }^{2}$, E. Gizewski ${ }^{3}$

University Institute of Diagnostic, Interventional and Pediatric Radiology, Inselspital, University Hospital Bern, Bern

Diagnostic and Interventional Radiology, University Hospital Giessen, Justus Liebig University Giessen, Gießen

Department for Neuroradiology, Innsbruck Medical University, Innsbruck

\section{Key words \\ - MR-imaging \\ - contrast agents \\ - gadolinium \\ - safety}

received 27.5.2013

accepted $\quad 2.12 .2013$

Bibliography

DOI http://dx.doi.org/ 10.1055/s-0033-1356403

Published online: 29.1.2014

Fortschr Röntgenstr 2014; 186:

661-669 ๑ Georg Thieme

Verlag KG Stuttgart · New York ISSN 1438-9029

\section{Correspondence \\ Herr Prof. Johannes \\ T. Heverhagen}

University Institute for

Diagnostic, Interventional and

Pediatric Radiology, Inselspital -

University Hospital Bern

Freiburgstr. 10

3010 Bern

Switzerland

Tel.: ++41/31/6322648

Fax: $++41 / 31 / 6324874$

Johannes.Heverhagen@insel.ch

\section{Abstract \\ $\nabla$}

Nephrogenic systemic fibrosis (NSF) is a serious, sometimes fatal disease. Findings in recent years have shown that a causal association between gadolinium containing contrast media and NSF is most likely. Therefore, the regulatory authorities have issued guidelines on the use of gadolinium-containing contrast media which have reduced the number of new cases of NSF to almost zero. However, it is for precisely this reason that the greatest care must still be taken to ensure that these guidelines are complied with. The most important factors are renal function, the quantity of gadolinium administered and coexisting diseases such as inflammation. All of these factors crucially influence the quantity of gadolinium released from the chelat in the body. This free gadolinium is thought to be the trigger for NSF. Other important factors are the stability of the gadolinium complex and furthermore the route of its elimination from the body. Partial elimination via the liver might be an additional protective mechanism. In conclusion, despite the NSF risk, contrast-enhanced MRI is a safe diagnostic procedure which can be used reliably and safely even in patients with severe renal failure, and does not necessarily have to be replaced by other methods.

Key Points:

- Despite the inherent risk of NSF, a MR investigation must not be denied to a patient provided there are sufficient indications and the possible benefits outweigh the risk.

- The risk of NSF can be minimized by adhering to the federal guidelines and using the minimal necessary Gd dose.

- It is recommended to measure the eGFR in all patients prior to the administration of a Gd-chelate. However, it is mandatory only when using agents of the high risk group.
- Gd-chelates should classified into two risk classes. No differences should be made between low and medium risk agents.

- Partial elimination of the agent by the liver may have a protective effect against NSF.

Citation Format:

- Heverhagen JT, Krombach GA, Gizewski E. Application of Extrcellular Gadoliniumbased MRI Contrast Agents and the Risk of Nephrogenic Systemic Fibrosis. Fortschr Röntgenstr 2014; 186: 661-669

\section{Zusammenfassung \\ $\nabla$}

Die Nephrogene Systemische Fibrose (NSF) ist eine schwerwiegende Erkrankung, welche auch zum Tode führen kann. Ein kausaler Zusammenhang zwischen gadoliniumhaltigen Kontrastmitteln und NSF ist aufgrund der Erkenntnisse der letzten Jahre als gegeben anzunehmen. Aus diesem Grund haben die Zulassungsbehörden die Kontraindikationen für die Anwendung gadoliniumhaltiger Kontrastmittel erweitert. Die Umsetzung dieser Anwendungseinschränkungen hat die Anzahl der neu aufgetretenen NSF-Fälle auf nahezu Null reduziert. Trotzdem sollte weiterhin streng auf die Einhaltung der Indikationen und Kontraindikationen geachtet werden, ohne dabei Patienten dringend indizierte Untersuchungen mit gadoliniumhaltigen Kontrastmitteln zu verwehren. Die wichtigsten Faktoren für die Entstehung einer NSF sind die eingeschränkte Nierenfunktion, die Menge des applizierten Gadoliniums sowie zusätzliche Erkrankungen wie beispielsweise Entzündungen und die hiermit einhergehende Absenkung des $\mathrm{pH}-$ Wertes. Diese Faktoren haben einen entscheidenden Einfluss auf die im Organismus aus dem Kontrastmittelchelat frei werdenden Gadoliniumionen, den mutmaßlichen Auslöser der NSF. Hinzu kommt die Stabilität des Gadoliniumkom- 
plexes und weiterhin auch der Ausscheidungsweg aus dem Organismus. Vermutlich stellt eine partielle Ausscheidung über die Leber einen zusätzlichen protektiven Mechanismus dar. Zusammenfassend kann festgehalten werden, dass die kontrastverstärkte MRT trotz des NSF-Risikos ein sicheres diagnostisches Verfahren darstellt, welches bei Beachtung der Anwendungsrichtlinien und aktuellen Empfehlungen auch bei Patienten mit schwerer Niereninsuffizienz sicher eingesetzt werden kann und nicht zwingend durch andere Verfahren ersetzt werden muss.

\section{Introduction}

$\nabla$

In 1997 Cowper and colleagues noted previously unknown fibrosing skin lesions in 15 patients [1]. All the patients required dialysis. The authors designated the skin lesions as "nephrogenic fibrosing dermopathy." After the initial description of this disease, the number of patients diagnosed with these lesions steadily increased. Thus J Perez-Rodriguez [2] reported 36.5 cases per 100000 MRI examinations between 2003 - 2006. It was quickly observed that the lesions were not limited to the cutis and subcutis, and the designation "nephrogenic fibrosing dermopathy" was replaced by the term "nephrogenic systemic fibrosis". Affected organs include the lung, pleura, skeletal musculature, heart, kidney and pericardium, among many others [3]. NSF occurs almost exclusively among patients presenting with a severe impairment of kidney function. As a rule, eGFR lies significantly below $15 \mathrm{ml} / \mathrm{min} / 1.73 \mathrm{~m}^{2}$, and the patient requires dialysis [4]. Neither ethnicity, gender nor age appear to play a significant role in the development of NSF [4].

Only in 2006, several years after Cowper's initial observation, was the relationship between the described changes and the administration of gadolinium-based contrast media ascertained $[5,6]$. Soon thereafter there were reports of 13 patients in Denmark. These patients likewise exhibited typical skin lesions after an MRI examination [7]. Numerous previous publications in recent years confirm the relationship between gadolinium-based contrast media and NSF, and causality between the administration of contrast agents and NSF can be considered a given [8]. However, cases of NSF have also been confirmed without prior administration of gadolinium-based contrast media $[9,10]$. Clear criteria for the diagnosis of NSF do not exist. Rather, the clinical history, physical examination and a biopsy indicating gadolinium deposits in the skin must be used for a diagnosis [4, 11].

\section{Overview}

$\nabla$

NSF is a serious, sometimes fatal disease. Characteristic changes affect the skin. Skin plaque, painful lesions as well as pruritus can occur. Characteristically the head and neck region are not affected, but rather only the trunk and extremities. An exception to the limitation to the trunk are the sclera, where yellow plaques may also occur [12]. Highgrade contractures have been observed with NSF which can lead to immobility, numerous patients have had to resort to wheelchairs. In severe cases of NSF, death has resul- ted from multi-system failure due to sclerotic transformation of organ systems.

The majority of the cases were initially reported in the USA. In contrast with most European countries, double or triple dosages of gadolinium chelate were administered. This could explain the relatively high number of NSF cases for the initially approved contrast agents gadopentetate dimeglumine (Magnevist ${ }^{\circledR}$ ) (1988) and gadodiamide (Omnis$\left.\operatorname{can}^{\circledR}\right)$ (1993) ( Table 1). However, it is clear that there are distinct differences among the various contrast media. The incidence of NSF can vary, depending upon the gadolinium chelate used ( $\bullet$ Table 2 ). Contrast media such as gadoteric acid (Dotarem ${ }^{\circledR}$ ) and gadobutrol (Gadovist ${ }^{\circledR}$ ) had not yet been approved during the period prior to the recognition in the United State of the relationship between administration of gadolinium and NSF ( $\bullet$ Table 1 ).

In the meantime, cases of NSF have declined and are rarely seen today [13]. This is due to the fact that shortly after the recognition of NSF and its connection to gadolinium-based contrast agents in 2006 [5], very effective countermeasures were found and consistently implemented. Thus in June 2006, the FDA issued an announcement indicating that in particular, high doses of gadolinium-based contrast media when eGFR $\leq 15 \mathrm{ml} / \mathrm{min} / 1.73 \mathrm{~m}^{2}$ should be administered only in cases of absolute necessity [14]. In May 2007, the FDA required manufacturers to include a warning notice in the Summary of Product Characteristics regarding patients with severe renal insufficiency [15]. In addition reference was made to other imaging procedures involving patients with moderate to severe renal insufficiency. The European authorities reacted similarly, and in Germany "Red Hand" letters were issued with approval restrictions for patients with renal insufficiency (2/2007 gadodiamide [16] and 6/ 2007 gadopentetate dimeglumine [17]). However, the reduced incidences of NSF should not result in ignoring these safety measures. Therefore, at-risk patients with limited renal function should not receive MRI contrast agents in the high-risk group, since strict compliance with the guidelines have resulted in the reduction of cases of NSF.

\section{Pathophysiology}

In cases of NSF, intracutaneously circumscribed lesions occur which may exhibit confluence in a fully-developed disease pattern. Characteristically CD34 + spindle cells (histiocytes and fibrocytes) deposits are found within dense collagen bundles and mucin deposits forming these lesions $[1,12]$. Here a significant accumulation of fibroblast-like

Table 1 Approval of extracellular and liver specific contrast media in the USA.

\begin{tabular}{lll} 
contrast media & & USA approval \\
\hline Gadopentetate dimeglumine & Magnevist $^{\circledR}$ & 1988 \\
\hline Gadoteridol & ProHance $^{\circledR}$ & 1992 \\
\hline Gadodiamide & Omniscan $^{\circledR}$ & 1993 \\
\hline Gadoversetamide & Optimark $^{\circledR}$ & 1999 \\
\hline Gadobenate dimeglumine & MultiHance $^{\circledR}$ & 2004 \\
\hline Gadoxetate disodium & Primovist $^{\circledR} /$ Eovist $^{\circledR}$ & 2008 \\
\hline Gadobutrol & Gadovist $^{\circledR} /$ Gadavist $^{\circledR}$ & 2011 \\
\hline
\end{tabular}


Table 2 NSF cases and relative frequency.

\begin{tabular}{|c|c|c|c|c|c|c|c|}
\hline \multirow[t]{3}{*}{ contrast media } & \multicolumn{3}{|c|}{ NSF cases } & \multirow{3}{*}{$\begin{array}{l}\text { contrast media } \\
\text { examinations global } \\
{[40,53-57]}\end{array}$} & \multirow{3}{*}{$\begin{array}{l}\text { NSF relative } \\
\text { frequency } \\
\text { (cases/1 million } \\
\text { applications) }\end{array}$} & \multirow{3}{*}{$\begin{array}{l}\text { NSF cases } \\
\text { (according to } \\
\text { German SPC) }\end{array}$} & \multirow{3}{*}{$\begin{array}{l}\text { contraindication with } \\
\text { eGFR }<30 \mathrm{ml} / \mathrm{min} / 1.73 \mathrm{~m}^{2}\end{array}$} \\
\hline & \multirow{2}{*}{$\begin{array}{l}\text { EU } \\
\text { BfArM } \\
{[39]}\end{array}$} & \multicolumn{2}{|l|}{ global } & & & & \\
\hline & & $\begin{array}{l}\text { EMA } \\
{[40]}\end{array}$ & $\begin{array}{l}\text { manufacturer } \\
{[53,54,56,57]}\end{array}$ & & & & \\
\hline Gadodiamide $\left(\right.$ Omniscan $\left.{ }^{\circledR}\right)$ & 165 & 438 & No data & 47 million & 9.3 & known & yes \\
\hline $\begin{array}{l}\text { Gadopentetate } \\
\text { dimeglumine }\left(\text { Magnevist }^{\circledR}\right)^{1}\end{array}$ & 23 & 135 & 123 & 115 million & 1.2 & known & yes \\
\hline $\begin{array}{l}\text { Gadoversetamide } \\
\left(\text { Optimark }^{\circledR}\right)\end{array}$ & 0 & 7 & No data & $>9$ million & 0.8 & known & yes \\
\hline Gadobutrol (Gadovist ${ }^{\circledR}$ ) & 4 & 1 & 2 & $>6$ million & 0.7 & known & no \\
\hline Gadoteridol (ProHance ${ }^{\circledR}$ ) & 1 & 1 & 1 & $>14$ million & $<0.1$ & known & no \\
\hline Gadoteric acid (Dotarem ${ }^{\circledR}$ ) & 1 & $1^{2}$ & 0 & $>21$ million & $<0.1$ & known & no \\
\hline $\begin{array}{l}\text { Gadobenate dimeglumine } \\
\text { (MultiHance }^{\circledR} \text { ) }\end{array}$ & 0 & 0 & 0 & $>11$ million & $<0.1$ & none & no \\
\hline
\end{tabular}

${ }^{1}$ Magnevist ${ }^{\circledR}$ and generics.

29 years prior to administration of gadoteric acid, the patient received a dose of another unknown gadolinium-based contrast medium. The case has not been conclusively assessed. "Table 2 was changed on February 18, 2014. The grey-scale value was incorrect.

cells in the lesions can be observed. Further, free gadolinium (as gadolinium; $\mathrm{Gd}^{3+}$ ) is directly demonstrable in the lesions [18]. Despite these characteristic findings, occurrence of NSF is known in its basic elements, but not explained in its entirety. Two factors appear to be of outstanding importance for the release of gadolinium from the chelate complex: (1) The applied quantity of gadolinium as well as (2) the significantly delayed elimination of the gadolinium-based contrast medium.

\section{Free Gadolinium}

Gadolinium is used for enhancing contrast in an MRI since at room temperature it demonstrates paramagnetic characteristics. A metal classified as a rare earth, gadolinium is employed in electrophysiology as a calcium channel blocker [19]. In its free form it is toxic (lethal dose for $50 \%$ of the population (LD50) for $\mathrm{GdCl}_{3}$ in mice $100-200 \mathrm{mg} / \mathrm{kg}$ [20]). In its uncombined form, gadolinium can cause neurological and cardiovascular symptoms [21]. In order to use gadolinium as a contrast agent despite its toxicity, it is bound with a chelate covalent into a complex. The available gadolinium chelates for MRI are structurally different, both chemically and physically. These can be composed linearly with a chain-shaped chelate molecule or macrocyclically with a ring-shaped chelate molecule; however, the macrocyclic complexes are more stable in vitro [22]. In addition to linear and macrocyclic distinctions, the charge of the complex must also be taken into account. Ionic complexes are more stable than the non-ionic form [22].

However, when considering the stability of gadoliniumbased contrast medium complexes, the different forms of stability should always distinguished [23]. Linear compounds can be characterized sufficiently accurately by the thermodynamic stability constants applicable to a $\mathrm{pH}$ of 14 , and the so-called conditional stability constants calculated for a $\mathrm{pH}$ of 7.4. Ionic linear contrast media are definitely more stable than non-ionic linear contrast media. In order to bind liberated gadolinium, excess free ligands are added to the latter. Unlike linear compounds, the stability of macrocyclic contrast agents is characterized by slower kinetics. Considerably more activation energy is required in order to release gadolinium from a macrocyclic chelate complex. Kinetic parameters at $\mathrm{pH} 1$ are determined in order to characterize the stability of the macrocyclic contrast medium. Based on this, extrapolation under various assumptions is performed. A comparison is very difficult due to the variety of parameters used to properly assess the stability of a contrast medium [23].

Gadolinium can separate from its chelate if other ions surrounding its binding site are competitive. Due to their similar radius, primarily phosphate, calcium, iron or zinc play a role here [24]. Interestingly, patients with kidney failure and raised phosphate and calcium levels are particularly susceptible to NSF [25].

\section{Additional Elimination via the Liver}

Until now, the type of elimination of the contrast medium with respect to different excretion routes has received little attention. All gadolinium-based MRI contrast agents are exclusively eliminated via the kidney with the exception of gadobenate dimeglumine (MultiHance ${ }^{\circledR}$ ) and gadoxetate disodium (Primovist ${ }^{\circledR}$ ). As a rule, NSF is observed only in patients exhibiting fulminant renal impairment [4]. Approximately $10 \%$ residual function (eGFR $>15 \mathrm{ml} / \mathrm{min} / 1.73 \mathrm{~m}^{2}$ ) appears to be sufficient to protect against NSF. Consequently NSF occurs rarely among patients with eGFR above $15 \mathrm{ml} /$ $\mathrm{min} / 1.73 \mathrm{~m}^{2}$ [26]. In a study including 83121 patients, Prince et al. reported an NSF rate of $0.5 \%$ in patients with an eGFR between 15 and $30 \mathrm{ml} / \mathrm{min} / 1.73 \mathrm{~m}^{2}$ [27]. Due to impaired renal function, gadolinium is retained longer in the body which can consequently set in motion the negative mechanisms for the development of NSF. Gadolinium-based MRI contrast media which are additional eliminated via the liver should exhibit an advantage with respect to the risk of NSF [28], since the contrast medium has a second elimination path despite delayed or inhibited excretion by the kidney. So far there are two contrast agents partially excreted by the liver. The first is gadoxetic acid which is excreted in approximately equal measure via the kidney and the hepatobiliary system. This contrast medium is used for MRI examination of the liver. Of the remaining gadolinium-based MRI contrast agents with a generally broad application 
spectrum, only gadobenate dimeglumine is additionally eliminated via the liver, but at a rate of only $5 \%$ [29]. A five percent elimination, converted, corresponds to an elimination (eGFR) of approx. $6 \mathrm{ml} / \mathrm{min} / 1.73 \mathrm{~m}^{2}$ via the kidney. This is not much for a healthy patient. However for patients at risk for NSF, this low elimination via the liver could play a significant role. Taking into account that a residual kidney function of about $10 \%$ (approx. $15 \mathrm{ml} / \mathrm{min} / 1.73 \mathrm{~m}^{2}$ ) generally suffices to protect against NSF, the alternate elimination path of this contrast agent via the liver, corresponding to $6 \mathrm{ml} / \mathrm{min} / 1.73 \mathrm{~m}^{2}$ should not be ignored. Potentially this portion is higher in the case of a patient with renal insufficiency. Elimination of gadobenate dimeglumine and gadoxetate disodium by the liver potentially contributes to the fact that despite the linear structure of these two contrast agents, no cases of NSF are known where these agents are used exclusively. Thus, despite their linear structure, these agents are not identified as contraindicated contrast media with respect to impaired kidney function, and therefore NSF.

\section{Lesion Development}

The exact mechanisms by which released gadolinium results in NSF must still be explained in its entirety. Investigations by Sieber et al. [30-32] have conclusively demonstrated that the chelate does not trigger NSF, but rather gadolinium. Interestingly, not only macrocyclic contrast agents did well with respect to the reduced frequency of NSF-like lesions. Contrast media additionally excreted via the liver also exhibited reduced gadolinium deposits in the skin [33]. However, it should additionally be considered that a rat exhibits higher hepatobiliary excretion of gadolinium-based contrast media than a human (gadobenate dimeglumine: $>30 \%$, gadoxetate disodium: $>70 \%$ biliary excretion) [34, 35].

Under physiological conditions, fibroblasts play a special role in scarring and wound healing [36]. Fibroblast activity is triggered by numerous non-specific events occurring within the context of injury and trauma to tissue. It is assumed that circulating fibrocytes are attracted by the toxic effects of free gadolinium. This is evidenced by the fact that free gadolinium can be demonstrated in the skin lesions of NSF patients [18]. By itself, however, gadolinium does not result in NSF. It is likewise known that NSF can occur among patients who have not received gadolinium-based contrast media [37]. In this respect gadolinium appears to play a role as trigger. In addition to released gadolinium, other factors may be influential, such as electrolyte imbalances, inflammation reactions, acidotic metabolic status and endothelial damage as well as thromboses. Some of these processes such as inflammations and related local acidosis or an acidotic total metabolic situation with a non-inflammatory genesis and electrolyte imbalances can, due to the change in $\mathrm{pH}$ value, lead to an alteration of the stability of the gadolinium chelate. It can therefore be presumed that the risk of developing NSF increases as these factors cumulate.

In summary it can be stated that the current model of NSF development is based on the assumption that local intracutaneous free gadolinium results in the release of osteopoetin by fibroblasts. Osteopoetin causes migration of macrophages which in turn absorb gadolinium intracellularly, and based on this defense mechanism, they release cyto- kines which attract fibroblasts that mature intracutaneously into fibrocytes locally and take on the phenotypes of spindle cells. In terms of faulty scar formation, these spindle cells form collagen fibers and hyaluronic acid while additionally releasing matrix metalloproteinase inhibitors such that the formed extracellular matrix cannot be sufficiently reduced. Numerous factors contribute to the development of NSF. These include: substantially impaired kidney function which reduces the excretion of the gadolinium chelate while the attendant acidosis limits the stability of the chelate, as well as other factors such as inflammation reactions, blood vessel damage and electrolyte imbalances.

\section{Current NSF Figures \\ $\nabla$}

\section{Uncertainty in Correlating NSF Cases with individual}

\section{Contrast Media}

A number of publications with case histories have appeared since the discovery in 2006 of the correlation between occurrences of NSF with the administration of gadoliniumbased contrast media. Without going into detail regarding their sources, Yang et al. in 2012 cited almost 1200 cases that had been reported to the Food and Drug Administration (FDA) [38]. However, it is difficult to make an unequivocal correlation of the cases to specific contrast agents, since the patients were frequently administered several agents within a short period, and the documentation with respect to the contrast media administered is incomplete, especially prior to 2006. NSF cases have been reported in numerous publications and databases, but not all have been uniquely associated with a specific contrast agent and/or have not been verified by biopsy. Further, there are double-counted cases, if a patient has received two or more different contrast agents, as well as inclusion of patients who have not been verified as having NSF. For these reasons we decided to compile for our review article only those cases which exhibit a definite association with a specific gadolinium-based contrast medium (so-called "unconfounded" cases) and which, to the extent possible, can also be histologically classified as NSF by means of a biopsy. Resources used were the databases of the EMA and BfArM as well as information provided by the contrast media manufacturers; for reasons identified above, we deliberately did not rely on certain other databases as well as reference sources.

\section{Overview of "unconfounded" NSF Cases}

On its web site, the European Medicines Agency (EMA) has published the number of worldwide known and verified cases for the various contrast agents. In a similar form, the BfArM worked this up for cases in the EU [39]. In addition, the various manufacturers have disclosed known cases related to their contrast media on their respective web sites or in other publicly-accessible publications ( $\boldsymbol{(}$ Table 2 ). For reasons already indicated, we have limited ourselves to these three official sources when representing the current numbers of NSF cases and have consciously not relied on cases mentioned in publications.

In order to weight these figures properly, the number of NSF cases must be juxtaposed against the number of examinations performed with the respective gadolinium chelate. If one divides the number of verified NSF cases by the number 
of applied doses, the result is a risk profile of the individual contrast media, which produces expected as well as some unexpected results. Thus, according to this distribution based on relative frequency, gadolinium-based contrast media can be divided into two classes. According to this gadodiamide forms the highest risk class (approx. 9 cases/1 million applications, dark grey), whereas all other contrast agents fall within a range of approx. 1 case/ 1 million applications or fewer. In principle this second class can be further subdivided: (a) contrast media in the range of approx. 0.1 1 case 11 million applications (medium grey) and (b) contrast media exhibiting a range of less than 0.1 case/ 1 million applications (gadoteridol, gadoteric acid, gadobenate dimeglumine) (light grey). However, one should keep in mind that the absolute number of NSF cases is low; therefore statistically reliable statements regarding the risk potential of the contrast agents are not possible, especially with respect to the non-high-risk contrast agents. It should be further noted that since 2007, gadodiamide, gadopentetate dimeglumine as well as their generics and gadoversetamide have been contraindicated for patients with impaired renal function (eGFR $<30 \mathrm{ml} / \mathrm{min} / 1.73 \mathrm{~m}^{2}$ ), and are no longer used for patients with this risk profile. Due to low utilization as well as its limitation to liver imaging, it did not appear to be useful to include gadoxetate disodium ( 0.15 million applications 2010 [40]) in the table of contrast agents. Dosage minimization is considered an important element in the prevention of NSF. When using gadobenate dimeglumine, there is the possibility to reduce the administered gadolinium dose without having to sacrifice important image information. This is due to its highest relaxivity (gadolinium effectiveness per molecule) of all extracellular standard contrast media [41-43]. Thus the proportion of gadolinium can be reduced by up to half $(0.05 \mathrm{mmol} / \mathrm{kg} \mathrm{BW})$, depending upon the medical issue and indications. This was also demonstrated in 2012 by the ESUR in the newly published Version 8.1 of its guidelines [44]. In the case of gadoxetate disodium, the applied dosage is significantly lower $(0.025 \mathrm{mmol} / \mathrm{kg} \mathrm{BW})$ since it is indicated exclusively for liver imaging. Currently gadobutrol is available only as a 1.0 molar solution and is therefore a double concentration compared to other common contrast agents which contain a concentration of 0.5 mole per liter. If the higher concentration is not taken into account, unintentional excess dosage may occur if equal volumes are administered compared to other agents (i.e. $0.2 \mathrm{mmol} / \mathrm{kg} \mathrm{BW}$ instead of $0.1 \mathrm{mmol} / \mathrm{kg} \mathrm{BW}$ ). This relative overdose could induce cases of NSF. Due to legal requirements, known cases of NSF are listed in the Summary of Product Characteristics (SPC) of the respective individual contrast agents.

\section{Current Guidelines issued by Regulators and Professional Societies \\ European Medicines Agency (EMA)}

In 2010 the CHMP (Committee for Medicinal Products for Human Use) of the European Medicines Agency (EMA) divided gadolinium-based contrast agents into three groups [40], based solely on their thermodynamic and pharmacokinetic properties. According to this assessment, contrast agents are classified as high, medium and low-risk with respect to NSF development ( $\bullet$ Table 3 ).

High-risk contrast media are gadopentetate dimeglumine, gadodiamide and gadoversetamide. Contraindications apply to these media for special risk groups (including eGFR $<30 \mathrm{ml} / \mathrm{min} / 1.73 \mathrm{~m}^{2}$ ).

Almost identical warnings are contained in the SPC for medium-risk contrast agents (gadobenate dimeglumine, gadoxetate disodium, gadofosveset trinatrium [in the USA Ablavar $^{\circledR}$ and earlier Vasovist ${ }^{\circledR}$ in the EU]) as well as lowrisk agents (gadoteric acid, gadobutrol, gadoteridol).

The high-risk category includes linear non-ionic contrast media (gadoversetamide and gadodiamide) as well as the linear ionic medium, gadopentetate dimeglumine. It can be easily seen here that the EMA classification is not stringently based on the thermodynamic and pharmacokinetic properties of the various contrast media. In the USA on the other hand, the American College of Radiology (ACR) [45] proposed a modified classification of gadolinium-based contrast media reflecting the number of cases of NSF.

\section{Food and Drug administration (FDA)}

In the United States, the FDA has issued warnings and contraindications for certain contrast agents. Information regarding the correlation between gadolinium-based contrast media and the etiology of NSF has been disseminated globally. Contraindica-

Table 3 European Medicines Agency.

\begin{tabular}{|c|c|c|c|c|}
\hline risk group & product & molarity [40] & chem. structure & action in EU 2010 \\
\hline \multirow[t]{3}{*}{ high } & Gadodiamide $\left(\right.$ Omniscan $\left.{ }^{\circledR}\right)$ & 0.5 & linear non-ionic & \multirow{3}{*}{$\begin{array}{l}\text { contraindication: } \\
\text { - eGFR }<30 \mathrm{ml} / \mathrm{min} / 1.73 \mathrm{~m}^{2} \\
\text { - hepato-renal syndrome } \\
\text { - newborn to } 4 \text { th week } \\
\text { caution: } \\
\text { - eGFR }<60 \mathrm{ml} / \mathrm{min} / 1.73 \mathrm{~m}^{2} \\
\text { - children }<1 \text { year } \\
\text { - no breast-feeding } 24 \mathrm{~h} \\
\text { renal function test mandatory }\end{array}$} \\
\hline & Gadoversetamide (Optimark $^{\circledR}$ ) & 0.5 & & \\
\hline & $\begin{array}{l}\text { Gadopentetate dimeglumine } \\
\text { (Magnevis } \mathrm{t}^{\circledR} \text { and generics) }\end{array}$ & 0.5 & linear ionic & \\
\hline \multirow[t]{3}{*}{ medium } & Gadobenate dimeglumine (MultiHance ${ }^{\circledR}$ ) & 0.5 & linear ionic & \multirow{6}{*}{$\begin{array}{l}\text { caution: } \\
\text { - eGFR }<30 \mathrm{ml} / \mathrm{min} / 1.73 \mathrm{~m}^{2} \\
\text { renal function test mandatory }\end{array}$} \\
\hline & Gadoxetate disodium (Primovist ${ }^{\circledR}$ ) & 0.25 & & \\
\hline & Gadofosveset trisodium (Vasovist ${ }^{\circledR}$ ) & 0.5 & & \\
\hline \multirow[t]{3}{*}{ low } & Gadoteridol (ProHance ${ }^{\circledR}$ ) & 0.5 & \multirow[t]{2}{*}{ macrocyclic non-ionic } & \\
\hline & Gadobutrol (Gadovist ${ }^{\circledR}$ ) & 1.0 & & \\
\hline & Gadoteric acid (Dotarem ${ }^{\circledR}$ ) & 0.5 & macrocyclic ionic & \\
\hline
\end{tabular}


tions have been established for gadodiamide, gadoversetamide as well as gadopentetate dimeglumine for patients with an eGFR $<30 \mathrm{ml} / \mathrm{min} / 1.73 \mathrm{~m}^{2}$. However, the FDA did not set concrete guidelines for the administration of gadolinium-based contrast agents.

\section{American College of Radiology (ACR)}

The ACR sought to fill this gap and issued recommendations for using gadolinium-based contrast media [45]. The guidelines are not founded on the characteristics of the contrast agents, but rather on the number of NSF cases in relation to the frequency of agent administration. The result is the following groups: gadopentetate dimeglumine gadodiamide, gadoversetamide belong to Group I "Agents associated with the greatest number of NSF cases;" whereas gadoteric acid, gadobutrol, gadobenate dimeglumine and gadoteridol were included in Group II, "Agents associated with few, if any, unconfounded cases of NSF."

Due to the low number of applications, no valid basis for of classification was found for a third group which includes gadofosveset trinatrium and gadoxetate disodium.

In principle, the classifications by the CHMP and ACR do not essentially differ. Gadodiamide, gadoversetamide and gadopentetate dimeglumine are contraindicated in both the USA and EU for certain risk patients (including renal insufficiency), whereas all other contrast media (cyclic and linear), including gadobenate dimeglumine and gadoxetate disodium only require a warning regarding this patient group. New are the ESUR guidelines which likewise support this twopart classification.

\section{European Society of Urogenital Radiology (ESUR) guidelines}

The ESUR has long concerned itself with the issue of contrast agents, both iodine- and gadolinium-based, and has issued extensive guidelines for the administration of these agents. Recently these guidelines were updated and are available as Version 8.1 [46].

The ESUR likewise proceeds from a classification of contrast media into two groups [47]. As is the case with the guidelines of the EMA, FDA and ACR, the agents gadopentetate dimeglumine, gadodiamide and gadoversetamide are assigned to the high-risk group for which there are contraindications for patients with an eGFR $<30 \mathrm{ml} / \mathrm{min} / 1.73 \mathrm{~m}^{2}$. For all additional contrast media (linear as well as cyclic) identical recommendations apply. Table 4 contains a list of these recommendations.

Recommendations for utilization of gadolinium-based contrast agents are also provided for pregnant woman and newborns. Contraindications exist for use of substances of the high-risk group for both patient groups. After administration of one of these contrast agents, breast feeding should be discontinued for 24 hours. In the event of strong indications, it is possible to use one of the non-contraindicated contrast media (gadoteric acid, gadobutrol, gadobenate dimeglumine, gadoteridol). When these agents are used, interruption of breast feeding is not recommended, but should weighed in discussion with the physician.

An additional frequently asked question concerns the administration of gadolinium-based contrast media to dialysis patients. The recommendations are unequivocal in this instance. If administration of a contrast agent is strongly indi-

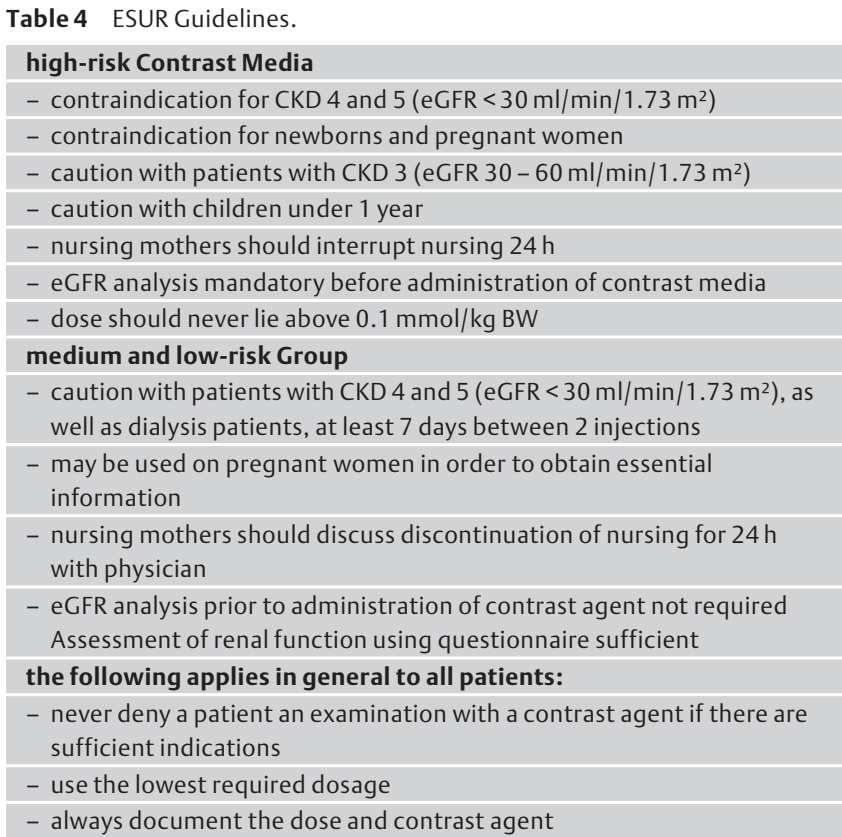

cated, it should be given as close as possible to the next dialysis session. There is no data to-date supporting dialysis performed directly after contrast agent administration as a protective measure. There is no recommendation to perform dialysis on a patient with severe renal impairment not otherwise requiring dialysis [47]. Both hemodialysis and peritoneal dialysis are suitable for removing contrast agents from the body, although hemodialysis is more effective. After one dialysis session, approx. $70 \%$ of the contrast medium is eliminated, > $90 \%$ after the second, and $98 \%$ after the third treatment [48].

An additional important aspect is discussed by the ACR. Patients with acute renal failure also belong in the group of patients at risk for developing NSF $[45,49,50]$. Since there is a temporal disconnect between the occurrence of acute renal failure and determination of serum creatinine values and thus eGFR values, particular attention should be paid to patients with known or suspected kidney failure, independent of measured serum creatinine or eGFR. In this case contrast agents should be administered only in the event or urgent indications, and no agent in the high-risk groups should be administered.

Particular attention should also be given to patients with total renal failure without residual elimination. Since with these patients no elimination of the gadolinium-based contrast medium can be expected, and since no further kidney damage can occur as a result of an iodine-based agent, computed tomography with an iodine-based medium should be preferred over an MRI with a contrast agent, assuming the result will clarify clinical questions [45]. There is an extremely low risk of developing NSF for patients whose eGFR lies above $30 \mathrm{ml} / \mathrm{min} / 1.73 \mathrm{~m}^{2}$. However, since a risk still exists, the lowest possible contrast medium dose should be administered here. It should be noted, however, that for the contrast agents of the high-risk group ( $\bullet$ Table 3 ), a warning applies to patients with moderate renal impairment (eGFR $<60 \mathrm{ml} / \mathrm{min} / 1.73 \mathrm{~m}^{2}$ ); therefore these agents should be used only after a careful risk-benefit analysis. 


\section{European non-EU Countries (Switzerland as example)}

Several European non-EU countries concur with the recommendations. Thus, for example, in Switzerland the EMA guidelines were practically implemented. Swissmedic published a relevant document "Safety-related Information on Gadolinium-based Contrast Media" [51 ]. In addition, changes were made to the Summary of Product Characteristics for all gadolinium-based contrast media in Switzerland, similar to the procedure in the USA.

\section{Recommendations for Utilization of Gadolinium-based Contrast Media in the Clinical Practice}

Recommendations can be derived from the above-mentioned publications, studies and their resulting guidelines.

Renal function notwithstanding, the use of contrast agents should always be carefully weighed. During their administration, the lowest possible dose required to obtained the required diagnostic result should be utilized. The following procedure can be recommended, depending upon renal function as measured by eGFR.

1. If the patient has impaired renal function (eGFR $<60 \mathrm{ml} /$ $\min / 1.73 \mathrm{~m}^{2}$ ), a contrast medium in the high-risk group ( $\odot$ Table 3 ) should be avoided.

2. If the eGFR value for a patient is below $30 \mathrm{ml} / \mathrm{min} /$ $1.73 \mathrm{~m}^{2}$, no high-risk contrast medium may be used. However, a contrast-enhanced MRI examination should be preferred over a contrast-enhanced CT examination, since the risk of NSF in this group is less than the risk of CIN.

3. In the case of high-grade renal function impairment (eGFR $<15 \mathrm{ml} / \mathrm{min} / 1.73 \mathrm{~m}^{2}$ ), two decisions must be made:

1. Residual diuresis

- Utilization only in the event of vital indication

- Administration of contrast agent only from the medium and low-risk groups ( $\bullet$ Table 3 )

- Clarification of NSF risk

2. No residual diuresis

- CT examination with contrast medium preferred, if possible for the relevant issue

Since patients without residual diuresis no longer have kidney function, there is no risk of contrast agent-induced nephropathy, and these patients can undergo a contrast-enhanced CT examination.

\section{Summary}

\section{What should be done?}

Apart from the still unclarified pathomechanism of NSF, the number of cases shows that the majority of NSF cases have occurred after the administration of those gadolinium-based contrast media contraindicated for patients with severe renal insufficiency (eGFR $<30 \mathrm{ml} / \mathrm{min} /$ $1.73 \mathrm{~m}^{2}$ ) ( $\odot$ Table 3). In individual instances, NSF has been observed after administration of solely macrocyclic contrast agents [52]. Therefore, the use of macrocyclic contrast agents does not diminish the duty of care to act in accordance with the warnings of the SPC. The additional biliary elimination as well as the lower possible dosages of gadobenate dimeglumine and gadoxetate disodium presumably contribute to the safety of both of these contrast agents since to-date no unconfounded NSF cases have oc- curred after their use. Almost all cases involving noncontraindicated contrast agents are associated with high dosages (single or cumulative). Numerous professional societies (e.g. ACR, ESUR) [45] recommend therefore, that atrisk patients be administered the lowest possible effective dose of gadolinium. This also concurs with the recommendations of the EMA [40]. However, it should be ensured in clinical practice that dosage is not incorrectly based on volume, but rather calculated based on gadolinium quantity in mmol, since some contrast media are not offered in the usual $0.5 \mathrm{M}$ concentration ( $\odot$ Table 3 ). Further, the relaxivity of the respective contrast agent should be noted. Compared to contrast agents with lower relaxivity, agents with higher relaxivity can be administered in smaller doses, so that the administered quantity of gadolinium can be significantly reduced while achieving the same image quality. Contrast agents in the high-risk group (gadopentetate dimeglumine, gadodiamide and gadoversetamide) may not be used on pregnant women and newborns; nursing must be interrupted for 24 hours after administration of these products. It is possible to use one of the non-contraindicated contrast media (gadoteric acid, gadobutrol, gadobenate dimeglumine, gadoteridol) if clearly needed. After administration of one of these agents, it should be discussed with the patient whether she would like to stop breast feeding for 24 hours.

Nevertheless it is important to keep in mind that NSF is currently a disease that very rarely occurs. If one counts all known unconfounded cases of NSF occurring with noncontraindicated contrast media as well as combination cases (confounded) using these agents exclusively, there are fewer than 10 NSF cases per 50 million applications worldwide. The number of cases of patients with NSF who have not received a high dose (single or cumulative), but rather a standard dose $(\leq 0.1 \mathrm{mmol} / \mathrm{kg} \mathrm{BW})$, is much lower. Despite the risk of NSF, it can still be maintained that contrast-enhanced MRI represents a safe diagnostic procedure which, if ESUR guidelines are followed, can also be reliably and safely used for patients with severe renal insufficiency and which does not necessarily have to be substituted by other procedures.

\section{Frequently Asked Questions and Answers}

$\nabla$

a) Does an eGFR assessment have to be performed for every patient?

Recommended but not mandatory, unless one of the contrast agents belongs to the high-risk group contraindicated for at-risk patients ( $\bullet$ Table 3 ).

b) May a contrast-enhanced MRI be performed at all on patients with eGFR values below $30 \mathrm{ml} / \mathrm{min} / 1.73 \mathrm{~m}^{2}$ ?

Yes, however, possibilities of alternative imaging methods as well as native MR should be investigated and consideration given to whether there is a clear need for a contrast-enhanced examination; contrast media belonging to the medium or low-risk groups must be used. The gadolinium dose should be as low as possible ( $\bullet$ Table 3 ).

c) According to applicable guidelines and recommendations, may only cyclic contrast agents be used with patients with eGFR values below $30 \mathrm{ml} / \mathrm{min} / 1.73 \mathrm{~m}^{2}$ ? 
No. All non-contraindicated contrast agents ( $\bullet$ Table 3 ) may be administered at the lowest possible gadolinium dosage after careful determination of indications and risk assessment.

d) What should be noted during examinations of patients with eGFR below $30 \mathrm{ml} / \mathrm{min} / 1.73 \mathrm{~m}^{2}$ ?

Use the lowest possible gadolinium dose (caution: not $\mathrm{ml}$ ), no application greater than via $0.1 \mathrm{mmol} / \mathrm{kg} \mathrm{BW}$. Repeat examinations should be performed only if clearly indicated, and then at an interval in excess of 7 days. No administration of contraindicated contrast media (॰ Table 3).

e) Are there absolutely safe contrast media with respect to NSF?

No. Even non-contraindicated contrast media pose a minimal risk.

\section{Literatur}

1 Cowper SE, Robin HS, Steinberg SM et al. Scleromyxoedema-like cutaneous diseases in renal-dialysis patients. The Lancet 2000; 356: $1000-1001$

2 Perez-Rodriguez J, Lai S, Ehst BD et al. Nephrogenic systemic fibrosis: incidence, associations, and effect of risk factor assessment - report of 33 cases. Radiology 2009; 250: 371 - 377

3 Kribben A, Witzke 0 , Hillen $U$ et al. Nephrogenic systemic fibrosis: pathogenesis, diagnosis, and therapy. J Am Coll Cardiol 2009; 53: 1621 1628

4 Jalandhara N, Arora R, Batuman V. Nephrogenic Systemic Fibrosis and Gadolinium-Containing Radiological Contrast Agents: An Update. Clin Pharmacol Ther 2011; 89: 920-923

5 Grobner T. Gadolinium - a specific trigger for the development of nephrogenic fibrosing dermopathy and nephrogenic systemic fibrosis? Nephrol Dial Transplant 2006; 21: 1104-1108

6 Marckmann P, Skov L, Rossen K et al. Nephrogenic Systemic Fibrosis: Suspected Causative Role of Gadodiamide Used for Contrast-Enhanced Magnetic Resonance Imaging. J Am Soc Nephrol 2006; 17: 2359-2362

7 Bennett CL, Qureshi ZP, Sartor AO et al. Gadolinium-induced nephrogenic systemic fibrosis: the rise and fall of an iatrogenic disease. Clinical Kidney Journal 2012; 5: $82-88$

8 Gupta A, Shamseddin MK, Khaira A. Pathomechanisms of nephrogenic systemic fibrosis: new insights. Clin Exp Dermatol 2011; 36: 763 - 768

9 Collidge TA, Thomson PC, Mark PB et al. Gadolinium-enhanced MR Imaging and Nephrogenic Systemic Fibrosis: Retrospective Study of a Renal Replacement Therapy Cohort. Radiology 2007; 245: 168-175

10 Wahba IM, Simpson EL, White K. Gadolinium Is Not the Only Trigger for Nephrogenic Systemic Fibrosis: Insights From Two Cases and Review of the Recent Literature. Am J Transplant 2007; 7: 2425-2432

11 Cowper SE, Boyer PJ. Nephrogenic systemic fibrosis: an update. Curr Rheumatol Rep 2006; 8: 151 -157

12 Cowper SE, Rabach M, Girardi M. Clinical and histological findings in nephrogenic systemic fibrosis. European Journal of Radiology 2008; 66: $191-199$

13 Becker S, Walter S, Witzke 0 et al. The German registry for nephrogenic systemic fibrosis: findings from 23 patients. Clin Nephrol 2010; 73: $426-430$

14 FDA Public Health Advisory. Gadolinium-containing Contrast Agents for Magnetic Resonance Imaging (MRI); 2006, www.fda.gov/Drugs/ DrugSafety/PostmarketDrugSafetyInformationforPatientsandProviders/DrugSafetyInformationforHeathcareProfessionals/PublicHealthAdvisories/ucm053112.htm (Stand 20.08.2013)

15 FDA. New warnings required on use of gadolinium-based contrast agents; 2007, www.fda.gov/NewsEvents/Newsroom/ PressAnnouncements/2010/ucm225286.htm (Stand 20.08.2013)

16 GE Healthcare. Wichtige Information zur Arzneimittelsicherheit Omniscan und nephrogener systemischer Fibrose. 2/2007 www.bfarm. de/SharedDocs/1_Downloads/DE/Pharmakovigilanz/roteHandBriefe/ 2007/rhb-omniscan.pdf?_blob=publicationFile (Stand 20.08.2013)

17 Bayer Health Care. Aktualisierte Sicherheitsinformation zu Magnevist und nephrogener systemischer Fibrose (NSF). 6/2007 www.akdae.
de/Arzneimittelsicherheit/RHB/Archiv/2007/46-20070625.pdf (Stand 20.08.2013)

18 High WA, Ayers RA, Chandler J et al. Gadolinium is detectable within the tissue of patients with nephrogenic systemic fibrosis. J Am Acad Dermatol 2007; 56: 21-26

19 Salomonsson M, Braunstein TH, Holstein-Rathlou NH et al. Na+-independent, nifedipine-resistant rat afferent arteriolar $\mathrm{Ca} 2+$ responses to noradrenaline: possible role of TRPC channels. Acta Physiol (Oxf) 2010; 200: $265-278$

20 Caille JM, Lemanceau B, Bonnemain B. Gadolinium as a contrast agent for NMR. Am J Neuroradiol 1983; 4: 1041 -1042

21 Penfield JG, Reilly RF Jr. What nephrologists need to know about gadolinium. Nat Clin Pract Nephrol 2007; 3: 654-668

22 Frenzel T, Lengsfeld $P$, Schirmer $H$ et al. Stability of gadolinium-based magnetic resonance imaging contrast agents in human serum at 37 degrees C. Invest Radiol 2008; 43: 817-828

23 Schmitt-Willich $H$. Stability of linear and macrocyclic gadolinium based contrast agents. Br J Radiol 2007; 80: 581 -582

24 Pietsch $H$, Pering $C$, Lengsfeld $P$ et al. Evaluating the role of zinc in the occurrence of fibrosis of the skin: A preclinical study. J Magn Reson Imaging 2009; 30: 374-383

25 Marckmann $P$, Skov L, Rossen $K$ et al. Case-control study of gadodiamide-related nephrogenic systemic fibrosis. Nephrol Dial Transplant 2007; $22: 3174-3178$

26 Rydahl C, Thomsen HS, Marckmann P. High prevalence of nephrogenic systemic fibrosis in chronic renal failure patients exposed to gadodiamide, a gadolinium-containing magnetic resonance contrast agent. Invest Radiol 2008; 43: 141-144

27 Prince MR, Zhang $H$, Morris $M$ et al. Incidence of nephrogenic systemic fibrosis at two large medical centers. Radiology 2008; 248: 807-816

28 Sato $T$, Ito $K$, Tamada $T$ et al. Tissue gadolinium deposition in renally impaired rats exposed to different gadolinium-based MRI contrast agents: Evaluation with inductively coupled plasma mass spectrometry (ICP-MS). Magn Reson Imaging 2013: Epub ahead of print

29 Kirchin MA, Pirovano GP, Spinazzi A. Gadobenate dimeglumine (GdBOPTA). An overview. Invest Radiol 1998; 33: 798-809

30 Sieber MA, Lengsfeld $P$, Walter J et al. Gadolinium-based contrast agents and their potential role in the pathogenesis of nephrogenic systemic fibrosis: the role of excess ligand. J Magn Reson Imaging 2008; 27: 955-962

31 Sieber MA, Steger-Hartmann T, Lengsfeld P et al. Gadolinium-based contrast agents and NSF: Evidence from animal experience. J Magn Reson Imaging 2009; 30: 1268 - 1276

32 Sieber MA, Pietsch $H$, Walter J et al. A preclinical study to investigate the development of nephrogenic systemic fibrosis: a possible role for gadolinium-based contrast media. Invest Radiol 2008; 43: 65 -75

33 Sieber MA, Lengsfeld P, Frenzel T et al. Preclinical investigation to compare different gadolinium-based contrast agents regarding their propensity to release gadolinium in vivo and to trigger nephrogenic systemic fibrosis-like lesions. Eur Radiol 2008; 18: 2164-2173

34 Lorusso V, Arbughi T, Tirone P et al. Pharmacokinetics and tissue distribution in animals of gadobenate ion, the magnetic resonance imaging contrast enhancing component of gadobenate dimeglumine $0.5 \mathrm{M}$ solution for injection (MultiHance). J Comput Assist Tomogr 1999; 23 (Suppl 1): S181-S194

35 Schuhmann-Giampieri G. Liver contrast media for magnetic resonance imaging. Interrelations between pharmacokinetics and imaging 167. Invest Radiol 1993; 28: $753-761$

36 Han G, Nguyen LN, Macherla C et al. Nitric Oxide-Releasing Nanoparticles Accelerate Wound Healing by Promoting Fibroblast Migration and Collagen Deposition. Am J Pathol 2012; 180: 1465 - 1473

37 Haemel AK, Sadowski EA, Shafer MM et al. Update on nephrogenic systemic fibrosis: are we making progress? Int J Dermatol 2011; 50: 659-666

38 Yang L, Krefting I, Gorovets A et al. Nephrogenic Systemic Fibrosis and Class Labeling of Gadolinium-based Contrast Agents by the Food and Drug Administration. Radiology 2012; 265: 248-253

39 Giersig C (BfArM). Sicherheit von gadoliniumhaltigen Kontrastmitteln unter dem Aspekt der Nephrogenen Systemischen Fibrose, Vortrag im Rahmen des Symposiums „Kontrast verstärkte MR-Untersuchungen praxisnah für den Alltag“ in Stuttgart 10/2010

40 EMEA. Assessment report for gadolinium-containing contrast agents; 2010, www.ema.europa.eu/docs/en_GB/document_library/ Referrals_document/gadolinium_31 / WC500099538.pdf (Stand 20.08.2013) 
41 Schneider G, Maas R, Schultze KL et al. Low-dose gadobenate dimeglumine versus standard dose gadopentetate dimeglumine for contrastenhanced magnetic resonance imaging of the liver: an intra-individual crossover comparison. Invest Radiol 2003; 38: 85 - 94

42 Achenbach $M$, Figiel JH, Burbelko $M$ et al. Prospective comparison of image quality and diagnostic accuracy of 0.5 molar gadobenate dimeglumine and 1.0 molar gadobutrol in contrast-enhanced run-off magnetic resonance angiography of the lower extremities. J Magn Reson Imaging 2010; 32: $1166-1171$

43 Bauner KU, Reiser MF, Huber AM. Low dose gadobenate dimeglumine for imaging of chronic myocardial infarction in comparison with standard dose gadopentetate dimeglumine. Invest Radiol 2009; 44: $95-104$

44 Thomsen HS, Morcos SK, Almen T et al. Nephrogenic systemic fibrosis and gadolinium-based contrast media: updated ESUR Contrast Medium Safety Committee guidelines. Eur Radiol 2013; 23: 307-318

45 American College of Radiology. Manual on Cotrast Media, Version 9; 2013, www.acr.org/ /media/ACR/Documents/PDF/QualitySafety/ Resources/Contrast\%20Manual/2013_Contrast_Media.pdf (Stand 20.08.2013)

46 ESUR. Guidelines Version 8.1; 2013, http://www.esur.org/guidelines/ en/index.php (Stand 20.08.2013)

47 ESUR. Summary NSF; 2013, http://www.esur.org/esur-guidelines/nsf (Stand 20.08.2013)

48 Yoshikawa K, Davies A. Safety of ProHance in special populations. Eur Radiol 1997; 7 (Suppl 5): 246-250

49 Kalb RE, Helm TN, Sperry H et al. Gadolinium-induced nephrogenic systemic fibrosis in a patient with an acute and transient kidney injury. $\mathrm{Br}$ J Dermatol 2008; 158: 607-610
50 Perez-Rodriguez J, Lai S, Ehst BD et al. Nephrogenic systemic fibrosis: incidence, associations, and effect of risk factor assessment - report of 33 cases. Radiology 2009; 250: 371 - 377

51 Bindschedler M Swissmedic; Sicherheitsrelevante Information zu gadoliniumhaltigen Kontrastmitteln. Schweizerische Ärztezeitung 2006: 87: 29/30 1323 www.saez.ch/docs/saez/archiv/de/2006/2006-30/ 2006-30-686.PDF (Stand 20.08.2013)

52 Elmholdt TR, Pedersen M, Jorgensen B et al. Nephrogenic systemic fibrosis is only found among gadolinium-exposed kidney-insufficient patients: a case-control study from Denmark. Br J Dermatol 2011; 165 : $828-836$

53 Guerbet. Updated safety information; 2011, www.guerbet.co.kr/ fileadmin/user_upload/websites/site_co/2011_28_FebruaryUpdated_information_about_NSF.pdf (Stand 20.08.2013)

54 Bayer. Reports of NSF/NSF-like symptoms in possible association with the administration of Gadolinium-based contrast agents of Bayer. www.diagnostic-imaging.bayerscheringpharma.de/html/pdf/hcp/nsf/ NSF_website_NSF_reports_Jan11.pdf (Stand 19.09.2011)

55 Neumann H. Optimark (gadoversetamide) U.S. Food and Drug Administration, Joint Meeting of the Cardiovascular and Renal Drugs and Drug Safety and Risk Management; 2009, www.fda.gov/ downloads/AdvisoryCommittees/CommitteesMeetingMaterials/ Drugs/CardiovascularandRenalDrugsAdvisoryCommittee/ UCM196229.pdf (Stand 20.08.2013)

56 Bracco. Info-Brief NSF. Auf Anfrage bei Services.professional@bracco. com, (Stand 20.08.2013)

57 Bayer Health Care. Briefing Document for Gadobutrol Injection; 2011, www.fda.gov/downloads/AdvisoryCommittees/ CommitteesMeetingMaterials/Drugs/ PeripheralandCentralNervousSystemDrugsAdvisoryCommittee/ UCM240357.pdf (Stand 20.08.2013)
Erratum (2.7.2015) to: “Application of Extracellular Gadolinium-based MRI Contrast Agents and the Risk of Nephrogenic Systemic Fibrosis. Heverhagen JT et al. Fortschr Röntgenstr 2014; 186: 661 -669”

We apologize for a translation error in the English version of this article. The sentence "The result is the following groups: gadopentetate dimeglumine, gadodiamide, gadoversetamide belong to Group I "Agents associated with the greatest number of NSF cases; (...)" was corrected with the correct term "gadopentetate"." 